\title{
La misión del embajador Juan Miguel Bákula en Santiago en mayo de $1986^{1}$
}

\author{
The Mission of Ambassador Juan Miguel Bákula in Santiago in May 1986
}

\section{Sebastián Flores Díaz}

sfloresabogado@gmail.com

Abogado y magíster en Derecho Público por la Universidad de Chile. Doctorando en Derecho, Universidad Autónoma de Madrid. Profesor de Derecho en la Escuela de Gobierno de la Universidad de Chile y profesor de Derecho Internacional en la Universidad UNIACC.

Resumen: El presente trabajo analiza la gestión desarrollada por el embajador peruano Juan Miguel Bákula en Santiago de Chile, en mayo de 1986. Como consecuencia de dicha misión, realizó la famosa presentación del día 23 de mayo de 1986, que inició formalmente el proceso por la delimitación marítima que culminó el 27 de enero de 2014 con la decisión de la Corte Internacional de Justicia. Esta misión tuvo su punto culmine con su célebre "memorándum", que se convirtió en el punto de inflexión de esta historia. También evalúa la recepción que tuvo Bákula en Chile y se compara la política exterior chilena y peruana así como el concepto y el rol que ocupa el Derecho Internacional en las mismas.

Palabras Clave: Memorándum Bákula, Delimitación de espacios marítimos, Cultura Jurídica y Derecho Internacional

\begin{abstract}
This paper analyzes the management developed by the Perwian Ambassador Juan Miguel Bákula in Santiago de Chile, in May 1986. As a result of this mission, he made the famous presentation of the day 23 of May 1986, which formally began the process by maritime delimitation which culminated on January 27, 2014 with the decision of the International Court of Justice. This mission took its ends with his famous "memorandum", which became the turning point of this story. Also, it evaluates the reception which had Bakula in Chile and compares foreign policy Chilean and Perwian as well as the concept and the role that international law deals them.
\end{abstract}

Key Words: Memorandum Bákula, Delimitation of Maritime Spaces, Legal Culture and International Law

1 Artículo enviado el 01.03.2019 y aceptado el 10.12.2019. 


\section{Introducción}

El presente trabajo revisa la misión del embajador Juan Miguel Bákula en 1986 y a la presentación de su célebre memorándum que inició formalmente el proceso de redelimitación marítima. Renouvin indica que la historia diplomática está influenciada primordialmente por hombres y sus actuaciones trazadas por la influencia de "fuerzas profundas" (Renouvin 1960: xi), cuestión que se aborda en este artículo.

Hay tres grupos de actores en la creación y ejecución de la demanda marítima del Perú. En primer lugar, los decisores políticos, como Alan García Pérez. También está el equipo científico jurídico, aquellos diplomáticos, juristas, científicos, historiadores, entre otros, que participaron realizando los estudios, redactando los informes y proporcionando los insumos para el caso. Finalmente están los estrategos, categoría en la que se sitúan el vicealmirante Guillermo Faura Gaig, o el mismo embajador Bákula. Ambos integraron la comisión negociadora del Perú en la Tercera Conferencia de las Naciones Unidas sobre Derecho del Mar, y estaban al tanto de las doctrinas chilenas sobre la naturaleza y alcance de los instrumentos internacionales de 1952 y 1954.

Carreño (2017: 23) indica que las "fuerzas profundas" corresponden a los elementos primarios constitutivos de identidad, que impulsan distintos procesos sociales, políticos, económicos, militares y culturales que marcan la trayectoria diplomática de un país. Estas fuerzas ir presiones impactan en los procesos de toma de decisiones, específicamente sobre aspectos, comportamientos y mecanismos que tienen su origen en las percepciones de los estadistas y decisores políticos, cuya actuación -en parte- está determinada por su personalidad y emociones. En el caso de la misión de Bákula las "fuerzas profundas" corresponden a los intereses peruanos sobre Arica, especialmente cuando se trata la solución a la mediterraneidad de Bolivia.

Renouvin (1960: x-xii) da mucha importancia a la figura del estadista como conductor de las relaciones internacionales y a las "fuerzas profundas" que influencian la toma de decisiones del estadista. La misión del embajador Bákula responde a un plan trazado por el presidente Alan García que pretendía fortalecer el Tratado de Paz y Amistad de 1929.

Con la misión se intentó recuperar la denominada "opción de paz", es decir, una política chileno-peruana conjunta para generar vínculos permanentes, en la que Bolivia fuese considerada como un tercero con intereses propios (Zapata 2012: 19), en la que que Chile y Perú renunciaban a la idea de crear una alianza con Bolivia, que sería percibida por el otro como una amenaza para su propia seguridad, como ocurrió en el acuerdo de Charaña. La 
opción de paz descansaba en la garantía que los futuros acuerdos entre Chile y Bolivia no afectarían los intereses del Perú (Bákula 2002: 968).

La reunión los cancilleres del Valle, de Chile, y Allan Wagner Tizón, de Perú, en 1985 fue un momento que inició una excelente relación bilateral, que servía para retomar la "opción de paz" que estaba explícita en el artículo 1 del Protocolo Complementario de 1929 (Bákula 2002: 1088). Para ello, era necesario un aggionarmiento del Tratado de 1929, y conversar sobre los espacios marítimos surgidos con ocasión de la CONVEMAR.

Bákula, cuando estuvo destinado en Chile, fue testigo de las discusiones jurídicas que hubo en torno a la Declaración de Santiago de 1952 y el Convenio sobre Zona Especial Fronteriza Marítima de 1954. Su experiencia en el servicio exterior y sus dotes intelectuales lo situaron como una autoridad en el naciente Derecho del Mar. Esa visión global le permitió plantear una estrategia para que su cancillería zanjara las cláusulas pendientes del Tratado de 1929, pero abriendo una discusión jurídica que disuadiera a Bolivia de revivir el acuerdo de Charaña. Ese era el objeto de la visita de 1986, pero la historia tomó un cauce diferente.

\section{La llegada de Bákula}

El embajador Bákula visitó a Santiago de Chile en mayo de 1986, como parte de la delegación del canciller Wagner. Llegó días antes que éste, como su "enviado especial", pues traía un mensaje importante para su país: plantear que no existía un tratado específico de límites marítimos entre Chile y Perú. Lo esperaba la prensa santiaguina ya que un cable de último momento había puesto en duda que Wagner realizara la visita ${ }^{2}$. En el mismo Palacio de La Moneda (donde funcionaba la Cancillería), Bákula habló con el vespertino La Segunda, que publicó lo siguiente:

\section{“Confirman viaje de Allan Wagner"}

"El embajador del Perú, experto en materias del Derecho del Mar, Miguel Bákula, se entrevistó hoy con el Canciller Jaime del Valle y posteriormente con el Director General de Política Exterior, Gastón Illanes. A la salida de estas reuniones señaló que el Ministro de Relaciones Exteriores del Perú había confirmado su visita a Chile"3.

2 La Segunda 28 de mayo de 1986.

3 La Segunda 23 de mayo de 1986. 
Bákula había participado, desde los inicios, en la discusión internacional sobre los espacios marítimos, y en la defensa del mar peruano, pero con perfil bajo (Bákula 1985: 419-432). Como intelectual fue el gran sistematizador del tema de la equidad en las fronteras marítimas con Chile, y de la tesis de la inexistencia de un tratado específico sobre delimitación marítima entre Chile y Perú.

En esas calidades, en 1986, Bákula fue el primero en plantear oficialmente (y con argumentos basados en los instrumentos internacionales vigentes) que había un problema jurídico con Chile en la zona fronteriza marítima. Sin embargo, el gobierno del general Augusto Pinochet estaba sobre aviso (o debió estarlo) por una gestión extraoficial de otro personaje peruano.

En una entrevista del año 2011, Hugo Otero, señaló que en julio de 1985 el recién electo Alan García lo envió a una misión extraoficial a Santiago (Rodríguez Elizondo 2014: 55). El contenido de la misión habría sido reservado. La misión tenía por objeto abrir un proceso de negociación para la ejecución de las cláusulas pendientes del Tratado de Paz y Amistad de 1929. También, explorar la reacción chilena ante la doctrina peruana de la inexistencia de un tratado específico de límites marítimos. Esta doctrina tenía asidero en la obra de varios juristas chilenos que desde 1955, discutían si Declaración de Santiago de 1952 y el Convenio de 1954 eran o no Tratados Internacionales, y también sobre la naturaleza de los mismos. Al momento de la gestión de Bákula, la opinión mayoritaria sostenía que se trataba de acuerdos pesqueros (Flores 2017: 67-78).

La gestión de Hugo Otero fue un sondeo político a Pinochet, quien se habría mostrado receptivo y dispuesto al diálogo pues “todo se podía conversar". Torre Tagle también había sondeado a diplomáticos chilenos sobre el tema (Fernández 2005: 14).

Tras el cometido de Otero, éste y el mismo García se reunieron con el joven diplomático Allan Wagner Tizón, quien sería canciller (Durán 2014: 21). Esta circunstancia abrió la oportunidad protagónica de Bákula. Wagner fue su alumno en la Academia Diplomática del Perú, y siempre lo consideró su maestro y amigo ${ }^{4}$. Bákula viajaría a Santiago como parte de la delegación de Wagner, y su designación como "enviado especial del canciller" le abrió las puertas del Palacio de La Moneda, donde funcionaba la Cancillería chilena. El mismo Wagner pidió a del Valle que lo recibiera.

La elección de Bákula también era una señal. La misión no se encomendó al embajador Luis Marchand Stens -acreditado oficialmente en Chile- y quien tuvo la importante misión de entregar la contrapropuesta peruana a Pinochet sobre los Acuerdos de Charaña en 1978.

4 Véase declaración de Allan Wagner con motivo del fallo de La Haya, disponible en la Web http://www.rpp.com.pe/2014-01-27-wagner--me-siento-orgulloso-y-honrado-de-haber-presidido-esteequipo-noticia 664969.html [Consulta 31 de diciembre de 2019].

Número de página no utilizable para citar 
Decodificada la situación, Pinochet y del Valle debían entender que estaban frente a un planteamiento de importancia fundamental.

Contrastando con esa importancia y aunque parezca insólito, no existe una versión chilena sobre lo tratado en los aproximados 60 minutos (Bákula 2002: 1150 - Bákula 2008: 214) que duró la conversación en solitario de Bákula con del Valle. La práctica diplomática señala que es costumbre contar con un tercero que pueda dar fe de lo tratado en la reunión, lo que no ocurrió en este caso. También se acostumbra entregar un comunicado inmediato cuando se tratan temas importantes (Nicolson 2012: 104). Eso tampoco ocurrió. Bákula explica que "en atención a aspectos protocolares, pero también por no existir razón alguna para dar publicidad a lo tratado, se acordó mantener el carácter confidencial de la entrevista” (Bákula 2002: 1151. Nota 141, las negritas son añadidas). El contenido de la reunión quedó en reserva por un breve tiempo, aunque la reunión no fue secreta. La prensa de la época dio cuenta de la reunión el mismo día que ocurrió. Sin embargo, no informó de su contenido hasta el 12 de junio, cuando la Cancillería chilena emitió un comunicado sobre la gestión de Bákula, que fue publicado por el diario El Mercurio al día siguiente, que señala:

"Con relación a las informaciones aparecidas en la prensa relativas a que se estaría desarrollando negociaciones entre Chile y el Perú, sobre la delimitación marítima de ambos países, el Ministerio de Relaciones Exteriores debe señalar lo siguiente:

1.- El Embajador peruano don Juan Miguel Bákula visitó recientemente la Cancillería chilena, oportunidad en que se trató la participación de ambos países en la comisión Permanente del Pacífico Sur, así como la necesidad de reforzar la acción de esta entidad.

En la oportunidad se intercambiaron también puntos de vista en cuanto a la posición de chile frente a la Organización Latinoamericana de Desarrollo Pesquero (OLDEPESCA).

2.- Durante esta visita, el Embajador Bákula dio a conocer el interés del Gobierno peruano para iniciar en el futuro conversaciones entre ambos países acerca de sus puntos de vista referentes a la delimitación marítima.

El Ministro de Relaciones Exteriores, teniendo en consideración las buenas relaciones existentes entre ambos países, tomó nota de lo anterior manifestando que oportunamente se harán estudio [sic] sobre el particular". 
La nota de El Mercurio finaliza indicando que versiones cablegráficas informaron que el canciller Wagner indicó en Lima que la delimitación marítima de acuerdo a la línea de los paralelos no coincide exactamente con la línea fronteriza ${ }^{5}$.

\section{El origen de la gestión}

El 11 de septiembre de 1973 finalizó un periodo de buenas relaciones entre Chile y Perú (Zapata 2012: 11-28). El general Juan Velasco Alvarado retomó la retórica belicista que caracterizó el inicio de su mandato en 1968. Su objetivo era recuperar Arica para el centenario de la Guerra del Pacífico. El general Pinochet tenía una amenaza real de conflicto armado con los tres vecinos de Chile, la temida HV3. En el caso de que Velasco Alvarado atacara a Chile, Bolivia y Argentina podrían sumarse al conflicto. La maniobra estratégica era reducir la HV3 a una HV2 (con Perú y Argentina) o a una HV1 (con Argentina por las disputas territoriales en el sur).

El gobernante boliviano Hugo Banzer apoyó la acción de las Fuerzas Armadas chilenas cuando derrocaron a Salvador Allende. Señaló que éstas interpretaban el deseo del pueblo chileno, cansado de los experimentos políticos e ideológicos de sus gobiernos (Bustos 2004: 221). Banzer y Pinochet tenían en común tanto una afinidad ideológica, como que ambos habían derrocado a gobiernos de izquierdas en sus respectivos países. Banzer era el aliado perfecto para Pinochet (Quitral 2010: 146).

Para asegurar la amistad con La Paz había que resolver el punto más espinudo en la relación bilateral: el acceso al Pacífico de Bolivia. Se tomó el modelo de las conversaciones WalkerOstria de 1950, pero con diferencias sustanciales, que obligan a analizar con distinto prisma el error político-diplomático de Gabriel González Videla y la maniobra coyuntural exitosa del general Pinochet que impidió la participación inmediata de Bolivia en una acción armada contra Chile.

Las conversaciones de 1950 tenían por objeto asegurar la amistad con el presidente de los Estados Unidos, Harry Truman, quien aparecía como el impulsor del entendimiento chilenoboliviano. González Videla quería acercarse a los Estados Unidos. En cambio, Pinochet quería evitar una guerra en el peor escenario internacional posible para Chile. Los acuerdos de Charaña (1975) cumplieron con ese objetivo estratégico inmediato de Pinochet. Bolivia

5 El Mercurio 13 de Junio de 1986.

Número de página no utilizable para citar 
reanudó las relaciones diplomáticas rotas en 1962, dejando en claro que no se sumarían a una acción bélica contra Chile. El corredor ofrecido creaba una buffer zone entre Chile y Perú, que en caso de una agresión peruana necesariamente afectaría el territorio boliviano. Velasco Alvarado y sus ministros interpretaron que Chile estaba listo para entregar el corredor al norte de Arica, y en caso de que se ejerciera el veto del Protocolo Complementario, habría un casus belli, que permitiría a Chile y Bolivia invadir el sur del Perú (Zapata 2014: 10).

Bákula sostuvo que Charaña fue el momento de mayor tensión en la relación chileno - peruana (Bákula 2002: 1119). Para él, la conquista de una buena relación nacida con el Tratado de 1929 se agrió con el entendimiento directo entre Chile y Bolivia. Fue contrario a que Santiago retomara contactos con La Paz que afectaran el estatus de Tacna y Arica.

Más lejos llegó el almirante Guillermo Faura que revisó los instrumentos jurídicos vigentes entre Chile y Perú, y las doctrinas de la Cancillería chilena sobre el tema. El almirante tomó el informe del embajador Raúl Bazán Dávila, en el que sostiene existe una delimitación marítima entre Chile y Perú, que pasa por el paralelo del punto en que la frontera terrestre llega al mar, que fue definida por un acuerdo, pero que no es posible determinar cuál es ese acuerdo (Faura 1977: 189-190).

Con estos antecedentes, Faura propone una negociación para solucionar el problema del "no tratado", y definir la frontera marítima, pero considerando la nueva realidad del naciente Derecho del Mar, donde se contemplan las ideas de la equidad y la equidistancia. Esta tesis tiene como corolario, en caso de que se cediera el corredor al norte de Arica, "Bolivia pasaría a ser de un país mediterráneo, a un país marítimo enclaustrado entre dos mares: el mar peruano y el mar chileno" (Faura 1977: 198-199). De este modo, prescinde de que Perú utilice el artículo $1^{\circ}$, del Protocolo Complementario, pues antes de esa hipótesis (hacer una cesión a Bolivia) es necesario definir los espacios marítimos de cada país.

Agrega que las negociaciones de Charaña se encuentran íntimamente ligadas al "Mar Peruano", y que el tema sobre la soberanía de Arica es "colocar el problema sobre su verdadera base". Incluso, emplaza a Morales Bermúdez a no dejarse avasallar por Chile, mediante una audaz cita a Alberto Ulloa Sotomayor, en la que el diplomático indicó que la solidaridad establecida en el Tratado de 1929 deja como iguales a Perú y Chile, y cada vez que Chile intenta por sí mismo resolver la mediterraneidad de Bolivia, vulnera esa igualdad (Faura 1977: 198-202).

La tesis de la inexistencia de un tratado específico de límites marítimos, no es contraria a la existencia de una frontera marítima, que pasa por el paralelo en que la frontera terrestre llega al mar. Ese deslinde entre ambos países nació de distintos instrumentos jurídicos, con diferentes alcances y propósitos. Durante la Tercera Conferencia sobre Derecho del Mar de las Naciones Unidas, Bákula indicó que el área donde Perú ejercería su jurisdicción y soberanía fue definida 
en $1947^{6}$. Es una referencia al decreto supremo $\mathrm{N}^{\circ}$ 781, de ese año, del presidente Bustamante y Ribero. En 1978, Bákula señaló que el "paralelo [...] constituye el límite marítimo entre ambos países [Chile y Perú] $]^{8 \%}$.

Torre Tagle tardó en adoptar la tesis de Faura, pues el almirante funda sus argumentos en la Convención de Ginebra de 1958, sobre mar territorial y zona contigua (Faura 1977: 194-195). En dicho instrumento, se desechó el paralelo como límite y se acogió la línea media, pero Perú y Chile no fueron parte de ese convenio. Es decir, en el momento en que Faura planteó su tesis, Torre Tagle no tenía buenos argumentos para defenderla, situación que cambió con la CONVEMAR que reconoció la equidad -no la línea media propuesta por Faura- como principio.

Bákula planteó por primera vez la inexistencia de un tratado específico de límites en 1985. En su libro "El dominio marítimo del Perú" defendió esta idea, y que la frontera marítima era inequitativa. Fundamentó su posición en que la CONVEMAR creó nuevos espacios y que el decreto $\mathrm{N}^{\circ}$ 781, de 1947, estaba superado por la realidad. Lo mismo ocurría con los instrumentos de 1952 y 1954 (Bákula 1985: 341-342). Esta idea la reitera en el párrafo $5^{\circ}$ del memorándum, en donde indica:

"En la actualidad, la existencia de una zona especial - establecida por la "Convención sobre Zona Marítima Fronteriza" - referida a la línea del paralelo del punto al que llega la frontera terrestre, debe considerarse como una fórmula que, si bien cumplió y cumple el objetivo expreso de evitar incidentes con "gentes de mar con escasos conocimientos de náutica", no resulta adecuada para satisfacer las exigencias de la seguridad ni para la mejor atención de la administración de los recursos marinos, con el agravante de que una interpretación extensiva, podría generar una notoría situación inequitativa y de riesgo, en desmedro de los legítimos intereses del Perú, que aparecerían gravemente lesionados."

6 Con la mención a este año, Bákula se refería al decreto supremo № 781, de 1947, del Presidente José Luis Bustamante i Rivero, a través del cual se fijó que el límite marítimo del Perú siguiendo los paralelos.

7 United Nations document A/CONF.62/C.2/SR.48, p. 77, disponible en http://untreaty.un.org/cod/diplomaticconferences/lawofthesea-1982/docs/vol IV/a conf-62 c-2 sr48.pdf. .

8 Dúplica Gobierno de Chile, Anexo 129, p. 813. 


\section{1986: el año decisivo}

En materia de política vecinal, el año 1985 fue exitoso. Los poderes legislativos aprobaron el Tratado de Paz y Amistad con Argentina de 1984. A finales de 1985, Allan Wagner se transformó en el primer canciller peruano en visitar Chile, cuando se reunió en Arica con su par, Jaime del Valle.

Éste último había firmado el Tratado con Argentina, y aparecía como la cara visible del acercamiento con Perú. La prensa solía consultarle si una vez que se zanjaran las cláusulas pendientes del Tratado de 1929, impulsaría un entendimiento con Bolivia. A del Valle le gustaba la posibilidad. También al general Pinochet, que podría presentarse como un estadista que consiguió la paz con Argentina, y que aseguró la amistad con Perú y Bolivia al resolver los asuntos pendientes, luego de una hipótesis de guerra en los 70's con los tres vecinos.

Desde Bolivia había expectativas en esta buena relación de Chile con Perú y Argentina. El cónsul general de Bolivia en Chile, Jorge Siles señaló que una vez que Chile resolviera los problemas pendientes con Perú y Argentina, iniciaría gestiones para solucionar los problemas con La Paz. En Bolivia se creía Pinochet tenía el poder absoluto para solucionar su mediterraneidad (Siles 2012: 71).

En febrero de ese año, el presidente boliviano Víctor Paz Estenssoro propuso una relación con "enfoque fresco". Un concepto ambiguo, en el que no se advertía la intención de iniciar una negociación para resolver el tema marítimo, sino el ánimo de fortalecer las relaciones económicas y comerciales con Chile (Andaluz 2002: 229). El entonces canciller Guillermo Bedregal sostuvo que era un intento para negociar una solución a la mediterraneidad boliviana. Pero fue un giro en la política exterior de ese país pues se dejó en segundo plano la ofensiva regional y se apostó por una conversación bilateral, similar a Charaña. Seguía presente la idea de que un corredor al sur la línea de la Concordia era la solución viable (Siles 2012: 85). Del Valle recogió con satisfacción el nuevo tono de La Paz, mucho más cordial, y respondió indicando que en Chile existía la voluntad de conversar y llegar a entendimientos con Bolivia.

El presidente Paz Estensoro y su canciller Bedregal, también apostaron a los vínculos familiares de los personajes chilenos involucrados para obtener resultados. El cónsul Jorge Siles era cuñado de del Valle. También se creyó que tendrían buena llegada con el general Pinochet, pues su hermana, residía en Bolivia, estaba casada con un ciudadano boliviano, y gozaba de estimación en La Paz (Bustos 2004: 259), lo que generó la creencia en los bolivianos que Pinochet era cercano a ese país.

Número de página no utilizable para citar 
El cónsul Siles tuvo la difícil tarea de conseguir una negociación similar a la de 1975. Para éste, el Perú era el principal responsable del fracaso de Charaña (Siles 2012: 121), por lo que decidió incluirlo desde un principio en sus gestiones. Cultivó la amistad del embajador peruano en Chile, Luis Marchand Stens, a quien informaba de las reuniones entre del Valle y Bedregal para preparar una negociación. El propósito era que no se pensara en Lima que las conversaciones se llevaban a espaldas del Perú (Siles 2012: 101). Marchand tenía información privilegiada sobre los pasos de la diplomacia boliviana, y remitía la información a Torre Tagle, que la procesaba.

\section{El encuentro Bákula - del Valle: la política exterior y el derecho internacional en Chile y Perú}

Bákula fue un intelectual y diplomático reconocido y respetado en Perú y Chile, al que las veleidades de la política interna peruana le impidieron ocupar los cargos más altos en Torre Tagle, como Canciller, Vicecanciller o Secretario General. Sólo ocupó puestos claves de forma interina. Estudió derecho, pero no era abogado de litigios, su actividad se centraba en la práctica diplomática y a la producción de libros. De la diplomacia aprendió que existe una permanente tensión entre la política y el derecho, la que tradujo como una contradicción entre cambio y estabilidad (Bákula 2002: 638). Sostenía que el acuerdo entre las partes era la fuente esencial del derecho internacional (Bákula 2002: 992).

Como director de la Academia Diplomática del Perú y como el primer director del Instituto Peruano de Relaciones Internacionales, fue un maestro de varias generaciones de diplomáticos y expertos internacionales. Participó de forma permanente en la delegación peruana en la Tercera Conferencia de la ONU sobre derecho del mar (1972-1979). Fue secretario general de la Comisión Permanente del Pacífico Sur, y miembro del Consejo Ejecutivo de la Comisión Oceanográfica Intergubernamental, con sede en París (COI - UNESCO) entre 1982 y 1986.

Su contraparte, el canciller Jaime del Valle, era un abogado dedicado al derecho procesal. Antes de ser canciller no ocupó ningún cargo diplomático. Su carrera profesional se desarrolló en el Consejo de Defensa del Estado. Su obra escrita es magra. En el catálogo de la Biblioteca Nacional de Chile aparecen cuatro títulos a su nombre. Dos de ellos son documentos de las carteras de Justicia (1963) y Relaciones Exteriores (1986), que realizó en su calidad de ministro.

9 El sitio Web de la Biblioteca Nacional le atribuye tres documentos a su autoría:

- Circular $N^{\circ} 1491$, de 28 de diciembre de 1963. Remite antecedentes para el Mensaje Presidencial. 
El contraste con Bákula era evidente. Si Bákula llegó como enviado especial del canciller Wagner, a tratar el tema de la inexistencia de un tratado de límites marítimos, por sus cualidades como intelectual y diplomático, del Valle llegó a ser Canciller por una mezcla de chapuzas diplomáticas y problemas internos de Pinochet.

Jaime del Valle ocupó el cargo de ministro de Relaciones Exteriores en 1983, luego de que su antecesor, Miguel Alex Schweitzer, no votara en contra de la Resolución $\mathrm{N}^{\circ}$ 683, de ese año, de la OEA (Figueroa 2007: 213). Esta declaración exhortó a Chile y Bolivia a "normalizar" sus relaciones "incluyendo en especial una fórmula que haga posible dar a Bolivia una salida soberana al Océano Pacífico"10. Schweitzer renunció a su cargo, el 19 de diciembre de ese año, sin que se le haya encomendado ninguna otra actividad gubernamental. Hasta ese momento, Jaime del Valle era el ministro de Justicia, pero Pinochet lo reemplazó con el abogado Hugo Rosende, y en un "enroque” ministerial, del Valle aterrizó en la Cancillería.

El encuentro entre Bákula y del Valle refleja el contraste entre ambas cancillerías. Bákula es un referente de la profesionalidad diplomática de Torre Tagle. Se le confió la misión no sólo por los afectos de Wagner, sino porque también era un experto en derecho del mar. Jaime del Valle fue canciller por por motivos de política interna, lo que explicaría la falta de respuestas de la cancillería en ese momento, por la falta de profesionalidad en su cúpula.

Bákula, como diplomático profesional e intelectual vino a tratar temas de fondo: la falta de un tratado específico de límites marítimos, y como solucionar el asunto de acuerdo al nuevo

- Estudios en honor de Pedro Lira Urquieta, de 1970, publicado por la editorial jurídica de Chile, donde figura como compilador junto con Tomás Mac Hale. En ese libro publicó un artículo entre las páginas 357 y 361 ,

- Constitución del Comité Chileno de Cooperación en el Pacifico, de 1986. Corresponde a una publicación del Ministerio de Relaciones Exteriores, de 22 páginas.

Información disponible en la Web http://descubre.bibliotecanacional.cl/primo library/libweb/action/search.do?vl(freeText 0$)=\% 20 \mathrm{Jaime} \% 20+$ $\% 20 \mathrm{del}^{2} \% 20+\% 20$ Valle $\% 20+1931$ -

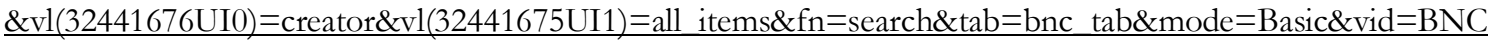
\&scp.scps $=$ scope $\% 3 \mathrm{a}$ (bnc aleph) $\% 2$ cscope $\% 3 \mathrm{a}$ (bnc digitool) $\% 2 \operatorname{cscope} \% 3 \mathrm{a}$ (bnc memoria) $\% 2 \operatorname{cscope} \% 3 \mathrm{a}(\mathrm{bn}$ c dtlmarc) [Consulta 31 de diciembre del 2019].

El catálogo de la Universidad Católica de Chile le atribuye seis obras. Dos de ellas en que figura como profesor guía de una memoria de grado, de 2002 y 2006, vinculadas al derecho procesal. Otras dos en que presenta un artículo sobre temas de derecho privado. También existe un artículo de 1988, de la Revista Chilena de Derecho - que edita esa casa de estudios- en que se refiere al fortalecimiento del poder judicial chileno. Por último, un discurso inaugural del año 1993, sobre justicia constitucional. Información disponible en la Web https://buscador.bibliotecas.uc.cl/primoexplore $/$ search?query $=$ creator, contains, jaime $\% 20 \mathrm{del} \% 20$ valle $\&$ tab $=$ libros tab\&search scope $=$ alma scope $\& \mathrm{v}$

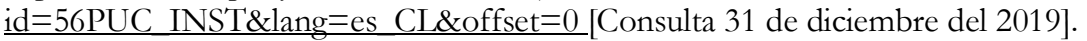

10 Resolución disponible en la Web http://www.oas.org/es/sla/docs/ag03797S01.pdf [Consulta 31 de diciembre del 2019]. 
derecho del mar. Del Valle, como abogado procesalista, se preocupó sólo de las formas y pidió que le entregaran un memorándum. Es el origen del memorándum Bákula, hoy famoso.

Las diplomacias son diferentes por la forma en que cada país concibe su política exterior. Desde una perspectiva realista de las relaciones internacionales, las políticas exteriores pueden enmarcarse en tres modelos: la política del "statu quo", en que un país tiende a conservar el poder y evitar el cambio de la distribución del mismo; la política del imperialismo, que busca aumentar su poder modificando la estructura del poder existente, cambiando el statu quo; y la política del prestigio, en la cual una nación tiende a mostrar el poder que tiene para mantenerlo o aumentarlo (Morgenthau 1986: 63-64).

La política exterior chilena es una política del statu quo, que pretende mantener una estructura de poder existente en un determinado momento histórico. Generalmente, la estructura generada luego de una victoria bélica, y asentada en los tratados de paz que establecieron la distribución de poder existente (Morgenthau 1986: 64-65). Esto explica la defensa unilateralista del derecho (Colacrai y Lorenzini 2005: 57), y el discurso oficial chileno de defensa irrestricta del derecho internacional escrito, con la creación criolla de un "principio de intangibilidad" de los tratados internacionales (Cabrera 2014: 132).

Perú, por su parte, tiene una política exterior de prestigio cuya finalidad "consiste en impresionar a otras naciones con el poder que nuestra propia nación realmente posee o con el poder que cree o que quiere que otras naciones crean que la nuestra posee", en la cual los diplomáticos juegan un papel primordial (Morgenthau 1986: 100-101). Por eso, Torre Tagle se preocupa de que sus profesionales ocupen lugares destacados en el sistema internacional. Por ejemplo, Víctor Andrés Belaunde fue presidente de la Asamblea General de Naciones Unidas en 1959, y además presidió el Consejo de Seguridad en tres ocasiones; José Luis Bustamante y Rivero fue el presidente de la Corte Internacional de Justicia entre 1967 y 1969; y Javier Pérez de Cuellar fue el Secretario General de Naciones Unidas entre 1981 y 1991. Hay que mencionar que Luis Alvarado también fue presidente, aunque de forma interina, de la Asamblea General de la ONU. Por último, recordar a Alfonso Arias-Schreiber, quien ocupó la Vicepresidencia de la III Conferencia de la ONU sobre Derecho del Mar.

La política exterior chilena centra la labor de la diplomacia en la defensa del derecho positivo. Se atribuye a Andrés Bello esta orientación juridicista (Colacrai y Lorenzini 2005: 58), sin embargo, no fue Bello quien realizó esta exaltación legalista. La exacerbación de esta idea se tradujo en el legalismo, una suerte de "esclavitud jurídica” (Barros van Büren 1970: 344).

Connotados funcionarios diplomáticos chilenos destacan el apego al legalismo como una virtud. El embajador Luis Melo indica que los Estados deben conducir sus relaciones diplomáticas de acuerdo a los principios del Derecho Internacional positivo, pues en su 
opinión "la soberanía del Estado no es absoluta [pues] está subordinada a la norma jurídica" (Melo 2004: 53). Complementa esta visión, René Rojas (canciller entre 1980 y 1983 ) quien destacó la importancia de ser abogado para ser un buen diplomático, pues el conocimiento del derecho internacional garantizaría la calidad profesional. Agrega que en todas las actividades diplomáticas aparece el derecho, y las negociaciones son más sencillas si se conocen las normas y principios jurídicos (Rojas 1984: 587-588). Opinión contraria a la de Francois de Calliéres, que consideraba que "en general, la formación de un abogado inculca hábitos y disposiciones intelectuales que no son favorables en la práctica de la diplomacia" (citado en Tomassini 1989: 247).

En Perú, la diplomacia se enmarca en el debate entre derecho y política exterior, sobre todo en los momentos de crisis (Pinto-Bazurco 2011: 21). Se entiende que existe un proceso de retroalimentación entre política, derecho y diplomacia (Pinto-Bazurco 2011: 35), pues en el ámbito internacional la política, o el poder, son concebidos como una herramienta para "la expansión de la influencia de un país así como para neutralizar la hegemonía de otros" (PintoBazurco 2011: 32). El derecho es visto como un mecanismo de plasmar esa realidad. El poder político pretende crear, modificar o derogar normas jurídicas conforme cambia la situación del Estado (Pinto-Bazurco 2011: 35).

La formación jurídica de Juan Miguel Bákula era muy diferente a la de Jaime del Valle, pues el derecho internacional se estudia, enseña y piensa de forma distinta en Chile y Perú. En Chile se cree que el derecho internacional es un sistema de reglas y principios similar a los ordenamientos internos, y se enseña como si se tratara de Derecho Civil, enfatizando los aspectos técnico-jurídicos (Fuentes 2004: 430). En Perú se entiende que hay una gran distancia entre el derecho interno y el derecho internacional (Bákula 2002: 1081).

Esta diferencia también se refleja en la producción intelectual chilena y peruana sobre el Derecho Internacional. En Perú el Derecho Internacional tuvo un gran estudio y desarrollo. No sucedió lo mismo en Chile. Para los abogados y juristas chilenos del siglo XIX, recién fue obligatorio estudiar Derecho Internacional en 1857, y se estudió hasta 1899 con el libro "Principios de Derecho Internacional' de Andrés Bello. Ese año, Miguel Cruchaga publicó 'Principios de Derecho de Jentes". No hubo mayor producción intelectual en Chile hasta finales de 1930 (Baeza 1937: 21-26).

En 1938 se publicó el esquema de clases de Ernesto Barros Jarpa, titulado "Derecho Internacional Público", y sólo se reeditaron las tres obras citadas ${ }^{11}$. Una de las obras más completas y

11 Hubo excepciones con libros de una sola edición como el "Manual de Derecho Internacional Público" de Rolando Peña López de 1961, o los “Cuadernos de Derecho Internacional” de Enrique Gajardo Villarroel, de 1966, o el "Manual de Derecho Internacional Público" de Claudio Bonnefoy. 
La misión del embajador Juan Miguel Bákula en Santiago en mayo de 1986

Sebastián Flores Díaz

difundidas en Chile es "Derecho Internacional Público" del peruano Alberto Ulloa. En Chile existen las ediciones de 1926, 1938 (publicadas en Lima) y 1957 (Madrid).

En 1976, Santiago Benadava publicó "Derecho Internacional Público". Entre 1977 y 1983, Hugo Llanos editó los tres volúmenes de "Teoría y práctica del Derecho Internacional Público". En 1978, Fernando Gamboa publicó el "Manual de Derecho Internacional Público". Posteriormente, sólo han existido nuevas ediciones de estas tres obras. A ello hay que añadir el trabajo de Edmundo Vargas Carreño "Derecho Internacional Público", publicado en Chile en 2006, que es una reedición aumentada de "Introducción al Derecho Internacional", de 1979, publicado en Costa Rica.

Hay libros sobre temas específicos de derecho internacional, por lo general con una sola edición, y escasa circulación. En las revistas académicas los artículos sobre Derecho Internacional, o temas vinculados a este tema y Chile son pocos.

En Perú se entendió que la discusión sobre el Derecho Internacional permitía aglutinar y organizar a los diplomáticos, junto con defender los intereses de país (Bákula 2007: 224-227). Al igual que en Europa (Koskenniemi 2014 A), los libros, y sobre todo, las revistas sobre el tema fueron vitales. A diferencia de Chile, la producción de obras de Derecho Internacional Público en los siglos XIX y XX fue mayor. Mientras en Chile se escribieron dos obras en el siglo XIX y ocho en el siglo $\mathrm{XX}^{12}$, en Perú se registran cinco tratados en el siglo XIX, siete en el Siglo $\mathrm{XX}^{13}$, y cuatro en el presente siglo ${ }^{14}$. Casi todas estas obras, fueron reeditadas $\mathrm{y} / \mathrm{o}$ reimpresas.

12 En el presente siglo sólo se han publicado reediciones de las obras de Benadava, Gamboa, Llanos y Vargas. También algunas obras colectivas, con buenos trabajos, pero sin sistematicidad.

13 Bákula, en "El Perú en el Reino de lo Ajeno", menciona los siguientes trabajos:

- José Silva Santisteban. Curso de Derecho Internacional o de Gentes. 1864. Segunda edición (la primera se publicó en 1858).

- Antenor Arias. Lecciones de derecho maritimo. Urna: Imprenta del Estado, 1876.

- Luis E. Albertini. Derecho diplomático, en sus aplicaciones especiales a las repúblicas sud-americanas. París: Librería de Rosa y Bouret, 1866. El autor era secretario de primera clase de la legación del Perú en Francia. Un siglo después,

- Félix Cipriano C. (Coronel) Zegarra. La condición Jurídica de los extranjeros en el Perú. Santiago de Chile: Imprenta de la Libertad, 1872. Fue un ilustrado funcionario diplomático.

- Ramón Ribeyro. Derecho internacional público. Dos volúmenes. Lima: Imprenta de E. Moreno, 1901 y 1906 (en la anteportada dice 1905).

- Alberto Ulloa, Derecho internacional público. Lima: Sanmani y Cia., 1926 y 1938, con una cuarta edición: Madrid, 1957.

- Raúl Ferrero Rebagliati. Derecho internacional. Tomo I. Lima: Academia Diplomática del Perú, Ediciones Peruanas, 1966 (sólo se publicó el tomo I).

- Felipe Portocarrero Olave. Derecho internacional público. Lima: Ediciones Peruanas, 1966.

- Javier Pérez de Cuéllar publicó su Manual de derecho diplomático (Lima: Academia Diplomática del Perú, 1964) con una segunda edición (México: Fondo de Cultura Económica, 1997).

- $\quad$ Luis Solari Tudela. Derecho internacional público. $3^{a}$ edición. Lima: Studium, 1986.

Número de página no utilizable para citar 
Ya en 1903 existían los conversatorios de Derecho Internacional, con importantes personeros públicos participando en ellos. De estos, se constituyó en 1913 la Sociedad Peruana de Derecho Internacional como filial del Instituto Americano de Derecho Internacional ${ }^{15}$. Bajo el alero de la Sociedad, nació la Revista de la Sociedad Peruana de Derecho Internacional (Bákula 2007: 297), que se edita desde 1940 hasta la actualidad, y cuenta con 155 números ${ }^{16}$.

Hay otro aspecto importante en el papel que ocupa el Derecho en la relación bilateral. Perú lo utiliza como defensa respecto de Chile. Tras la victoria sobre el ejército peruano en 1881, Chile ocupó Lima y la costa peruana, por ende, la administración pública y la prensa estaba controlada por chilenos (MacEvoy 2011: 335-405) que se consideraban "respetuosos de la ley". La normativa peruana se siguió aplicando en las zonas ocupadas, y la Corte Suprema del Perú continuó funcionando, situación que la constituyó en una defensora eficaz contra los eventuales abusos de los ocupantes (MacEvoy 2011: 369-370). El uso del derecho también sirvió a Perú para defender Tacna, pues se alegó que Chile ocupaba la zona sin ningún título jurídico (Ulloa 1926: 178-179). Los peruanos comprendieron el reflejo chileno de parecer respetuosos de la ley, y lo ocuparon en su favor.

La reunión de Bákula y del Valle fue una confrontación de culturas jurídicas que continuó hasta el fallo de La Haya. El concepto de cultura jurídica se refiere, entre otras cosas, a la ideología que se tiene en una sociedad respecto de la función del derecho (Tarello 1995: 24), que corresponde a los valores y actitudes que prevalecen en una comunidad (Squella 1992: 30), a un ethos que explica la manera de entender, aplicar y enseñar el derecho (Barahona 2010: 428). Ambas culturas jurídicas encuentran su origen en la tradición española, pero su desarrollo fue muy diferente tras la independencia. Las doctrinas jurídicas europeas tuvieron una recepción

Véase Bákula (2007). pp. 226-227, nota 11.

14 Asimismo, en la Biblioteca Nacional del Perú, aparecen las siguientes obras (aparte de las ya mencionadas por Bákula):

- Beatriz Ramacciotti de Cubas (directora). Derecho internacional público. (Lima, Pontificia Universidad Católica del Perú). 1991.

- Fabián Novak Talavera y Fernando Pardo Segovia. Derecho diplomático: comentarios a la Convención sobre Relaciones Diplomáticas. (Lima, Pontificia Universidad Católica del Perú). 2001.

- Fabián Novak Talavera y Luis García-Corrochano Moyano. Derecho internacional público. (Lima, Pontificia Universidad Católica del Perú). 2001 a 2005, con tres tomos.

- Pablo Revilla Montoya. Temas controvertidos del derecho internacionaly las relaciones internacionales. (Lima, Grupo Time). 2011.

- Elizabeth Salmón. Curso de derecho internacional público. (Lima, Pontificia Universidad Católica del Perú). 2014.

15 Véase http://www.spdi.org.pe/index.php/en/quienes-somos/nuestra-historia [Consulta 31 de diciembre de 2019].

16 El sitio de la Sociedad Peruana de Derecho Internacional están disponibles los 155 números de la "Revista Peruana de Derecho Internacional", Véase http://www.spdi.org.pe/index.php/en/revistas/revistas-actuales [Consulta 31 de diciembre de 2019].

Número de página no utilizable para citar 
distinta en cada cultura, y se aplicaron pensando en las nuevas realidades nacionales, lo que rompió la unidad inicial (Ramos 2014: 24).

La cultura jurídica chilena tuvo la influencia principal de la escuela francesa de la exégesis (Quintana 2006: 216-250), que solo considera la ley escrita como fuente principal del Derecho (Tarello 1995: 70-82), cuya interpretación se realiza con un apego rígido a la literalidad del precepto (Barahona 2010: 434), y con influencia hasta el presente (Barahona 2010: 433). Esta concepción resulta contraria al carácter consuetudinario del Derecho Internacional, y ha tendido a aislar al mismo de su contexto histórico, cultural y político (Van Klaveren 2012: 762). Además, se privilegia el derecho nacional por sobre las normas internacionales (Squella 2001: 563).

En Perú, la escuela de exégesis no tuvo la misma influencia. El iusnaturalismo fue relevante en la formación del sistema jurídico peruano. El positivismo fue "tenue", en contraste del "vigoroso" iusnaturalismo (Sobrevilla 2013: 209), que pudo justificar el derecho legislado (Gonzales 2009: 146), pues supeditó lo jurídico a la moral (Gonzales 2009: 133). De este modo, los juristas peruanos buscaron la justificación de su sistema fuera de la ley positiva (Gonzales 2009: 145). La interpretación siempre estuvo fuera del derecho positivo. Por ello, la influencia de "teorías puras" del derecho, como la de Hans Kelsen, que excluía cualquier consideración política o moral del derecho, no fue significativa (Sobrevilla 1973: 154-162).

\section{La secuela de la reunión}

La instrucción de Wagner había sido sólo “conversar” el tema, pero fue del Valle quien le pidió el “ayuda memoria” (Bákula 2002: 1150 / Bákula 2008: 2016). Según cuenta él mismo Bákula, acto seguido fue a la legación del Perú en donde le pidió al embajador Marchand que se quedara junto con él, y redactó el memorándum que presentó esa misma tarde en la Cancillería Chilena (Bákula 2008: 2017). La prisa de Bákula genera dudas. Si sólo se quería "conversar" del tema, pudo esperar hasta el día domingo 25, para consultar a Wagner si entregar o no el "memo" que le pidió del Valle.

El día lunes 26 de mayo, la prensa anunció con gran optimismo que el canciller Allan Wagner arribó a Santiago el día anterior. Se auguraba que la negociación de las cláusulas pendientes del Tratado de 1929 sería exitosa. Hubo una reunión el mismo domingo entre Wagner y del Valle que fue calificada como exitosa.

Número de página no utilizable para citar 
El lunes 26 hubo un desayuno de trabajo con el general Pinochet, luego del cual, del Valle anunció que "sólo existía un problema de índole jurídico" con el Perú relativo a las facilidades que se le darían en Arica.

Wagner planeó pasar por La Paz luego de su visita a Santiago, pero la canceló luego de las reuniones que tuvo en Chile y volvió a $\operatorname{Lima}^{17}$. Recién el 2 de junio viajó a Bolivia y se reunió con su homólogo, Guillermo Bedregal, para tratar, entre otros temas, la mediterraneidad boliviana. Wagner fue consultado acerca de un eventual entendimiento entre Chile y Bolivia sobre este punto, y respondió que el Tratado de 1929 obliga a "no ceder territorios comprendidos [...] en las provincias de Tacna y Arica a terceros países"18, pero que su país estaba dispuesto a considerar "un posible acuerdo donde Perú tuviera una participación con referencia al territorio de Arica" 19 .

El día 4 del mismo mes, la prensa informó que habría fracasado un acuerdo peruano-boliviano por la solución de la mediterraneidad boliviana ${ }^{20}$. Trascendió a la prensa que Bedregal emplazó a Wagner para conocer la posición peruana ante una eventual cesión de un corredor soberano al norte de Arica, sin que éste respondiera.

Jaime del Valle debió aclarar que no existía una negociación con Bolivia, sino que "conversaciones tendientes a un acercamiento". Enfatizó que la solución de los asuntos pendientes con el Perú era previa al inicio de las conversaciones con Bolivia ${ }^{21}$, aunque se trataba de procesos independientes entre sí. La bomba estalló el lunes 9 de junio, cuando La Segunda publicó en su sección Top Secret la siguiente nota:

\section{Negociación con Perú}

"Un alcance inesperado dentro de la negociación que se lleva adelante con Perú habría tenido la visita a Santiago -en los mismos días que estuvo acá el Canciller Alan [sic] Wagner- del embajador especial Miguel Bákula, el principal experto peruano en delimitación marítima."

"Bákula habría planteado el tema de la delimitación marítima en la frontera peruano-chilena materia que estima es de larga negociación. Desarrollarla en paralelo con el avance de cumplimiento del tratado de 1929 -en el cual se han logrado progresos de importancia- podría dificultar el despacho y materialización de esta última”22.

\footnotetext{
La Segunda, 28 de mayo de 1986.

18 El Mercurio, 3 de junio de 1986.

19 El Mercurio, 3 de junio de 1986.

20 El Mercurio, 4 de junio de 1986.

1 El Mercurio, 6 de junio de 1986.

2 La Segunda, 9 de junio de 1986.
} 
Se le consultó a Allan Wagner por esta nota y respondió que "Perú y Chile están trabajando en la delimitación marítima de sus aguas", pues si bien la Declaración de Santiago estableció la norma del paralelo como frontera marítima, este criterio resulta inconveniente para el Perú ${ }^{23}$.

El día 12 de junio, el embajador chileno Pablo Valdés leyó la declaración oficial de la cancillería chilena. Sin embargo, la noticia fue publicada con el título "Oportunamente estudiarán a delimitación marítima", indicando en la bajada de texto que la "Cancillería chilena entregó ayer un comunicado en relación a informaciones provenientes de Lima, donde se indicaba que se estaban desarrollando negociaciones en tal sentido" 24 .

Considerando el comunicado, aparece una incongruencia sobre la gestión en la obra escrita de Bákula. La primera se refiere al "carácter confidencial” de la reunión (Bákula 2002: 1151 nota 148). Queda claro que la visita y la reunión no fueron secretas. Otro aspecto misterioso está en que Jaime del Valle a la inversa de Bákula, y sin mencionarlo nominativamente, dice que se trataron otras materias en su reunión. En una entrevista indicó que, al iniciarse el proceso conocido como "Enfoque Fresco" con Bolivia, "se presentó en la Cancillería chilena un Embajador de la República del Perú que no era el acreditado en Chile para plantearme las reservas de su país en torno a la gestión en ciernes con Bolivia” (Tapia y Mardones 2011: 312).

\section{Balance de la visita}

El memorándum reconoció la existencia de una demarcación, pero que no estaba establecida por ningún tratado específico. El mismo Bákula sugiere, implícitamente, que existen poderosos elementos para considerar que el límite marítimo se fijó de forma consuetudinaria (Bákula 1985: 330). Para la cultura jurídica chilena (influenciada por la Escuela de la Exégesis, el positivismo jurídico, y su exacerbación kelseniana) la noción de un límite establecido por la costumbre no tenía cabida. La mayoría de los abogados y juristas están formados en la convicción de que el Código Civil es la principal norma jurídica del país, y en él la costumbre no tiene fuerza normativa, a menos que la ley se remita expresamente a ella.

Hay que añadir que la misma Declaración de Santiago de 1952, se plantea como una proclama de la "política internacional marítima", de los países signatarios. Esto era inaceptable para la mentalidad positivista chilena, en la que existe la creencia de que el derecho es un producto aséptico libre de toda "polución política", similar a muchos países occidentales, en los cuales

23 El Mercurio, 12 de junio de 1986.

24 El Mercurio, 13 de junio de 1986 (el subrayado es de este trabajo). 
deliberada y sistemáticamente se intenta separar el derecho de la política (Nino 2014: 15). A nivel del derecho interno, se puede obviar este vínculo, pero a nivel internacional la situación es diferente, pues la interacción entre derecho y política es difícil de desentrañar (Shaw 2012: 11).

\section{Referencias bibliográficas}

ANDALUZ, Horacio (2002). Bases jurídicas para la reintegración marítima de Bolivia. La regla pacta sunt servanda como punto cero. Santa Cruz: Universidad Privada de Santa Cruz de la Sierra.

Aron, Raymond (1985). Paz y guerra entre las naciones. Madrid: Alianza Editorial.

BAÉZA, Mario (1937): "Los estudios de derecho internacional, después de la publicación de la obra de Bello", Boletín del Seminario de Derecho Público 9. Santiago: Escuela de Ciencias Jurídicas y Sociales de Santiago: 21-26.

BÁKulA, Juan Miguel (1985). El dominio marítimo del Perú. Lima: Fundación M. J. Bustamante de la Fuente.

BÁKulA, Juan Miguel (1994). “Dos percepciones: espacio oceánico y uso pacífico”. Para este trabajo se contó con una separata que el mismo Bákula imprimió y distribuyó.

BÁKULA, Juan Miguel (2002). Perú: entre la realidad y la utopía. 180 años de política exterior. Lima: Ed. Fondo de Cultura Económica.

BÁKUlA, Juan Miguel (2007). El Perú en el reino de lo ajeno. Historia interna de la acción externa. Lima: Fondo Editorial Universidad de Lima.

BÁKULA, Juan Miguel (2008). La imaginación creadora y el nuevo régimen jurídico del mar. Perú y Chile: ¿el desacuerdo es posible? Lima: Editorial Universidad del Pacífico.

BARAHONA, Jorge (2010): "La cultura jurídica chilena: apuntes históricos, tendencias y desafíos”, en Revista de Derecho de la Pontificia Universidad Católica de Valparaíso 35: 427 448.

BArRos van BÜREn, Mario (1970). Historia diplomática de Chile. 1541-1938. Santiago: Ediciones Ariel.

BASADRE, Jorge (1985) Historia del derecho peruano. Lima: Edigraf.

BERNAL, Juan (1938). El tratado de Lima de 1929. Memoria de prueba para optar al grado de licenciado de la Facultad de Ciencias Jurídicas y Sociales de la Universidad de Chile. Santiago: Universidad de Chile. 
Bello, Andrés (1864). Principios de Derecho Internacional. Librería Garnier Hermanos.

Brownlie, Ian (2012). Principles of Public of International Law. Oxford: Oxford Univresity Press.

Bustos, Carlos (2004). Chile y Bolivia. Un largo camino de la independencia a Monterrey. Santiago: RIL Editores.

CABReRA, Lester (2014). Percepción y geopolítica en la relación Chile-Perú: desde el acta de ejecución hasta la demanda en La Haya. Santiago: Sin sello editorial.

CARreño, Eduardo (2017). Política exterior de Nigeria: visión internacional de Olusegun Obasanjo y sus implicaciones en la seguridad de África occidental (1999-2007). Tesis para optar al grado académico de doctor en Ciencia Política. Madrid: Facultad de Derecho, Universidad Autónoma de Madrid.

COLACRAI, Myriam y LORENZINI, María Elena (2005). "Política exterior de Chile: ¿Excepcionalidad o continuidad? Una lectura combinada de "fuerzas profundas" y tendencias", en Confines 1(2): 45-63.

DuRÁn, Phillip (2014). La hora de los halcones. La trastienda del conflicto Chile-Perú en La Haya. Santiago, Editorial Planeta.

FAURA, Guillermo (1977). El mar peruano y sus límites. Lima: Imprenta Amauta.

FERNÁNDEZ, Juan José (2005). "El límite marítimo chileno-peruano”, en Boletín de la Academia Chilena de la Historia LXXXI (114). Santiago, Academia Chilena de la Historia: 11-18.

FigueroA, Uldaricio (2007). La demanda marítima boliviana en los foros internacionales. Santiago: RIL Editores.

FLORES, Sebastián (2017). El memorándum Bákula. Un agujero negro en la política exterior chilena. Tesis para optar al grado de magíster en derecho. Santiago: Facultad de Derecho, Universidad de Chile.

FUENTES, Ximena (2004). "Modelos para enseñar a pensar en Derecho Internacional”, en Jornadas de Derecho Internacional. Estados Unidos: Organización de los Estados Americanos.

BASADRE, Jorge (1985). Historia del derecho peruano. Lima: Edigraf.

KosKEnNIEMI, Martti (2005). El discreto civilizador de naciones. El auge y la caída del Derecho Internacional 1870-1960. Madrid, Editorial Ciudad Argentina.

Koskenniemi, Marti (2014 A): "La política del Derecho Internacional”, Revista Latinoamericana de Derecho Internacional (LADI), (1). 
KosKenNiEmI, Marti (2014 B): "La política del Derecho Internacional. 20 años después", Revista Latinoamericana de Derecho Internacional (LADI), (1).

MAcEvoy, Carmen (2011). Guerreros civilizadores. Política, sociedad y cultura en Chile durante la guerra del Pacífico. Santiago: Ediciones Universidad Diego Portales.

MELO, Luis (2004). Diplomacia contemporánea. Teoría y práctica. Santiago: RIL Editores/ADICA.

Morgenthau, Hans (1986). Política entre las naciones. La lucha por el poder y la paz. Buenos Aires: Grupo Editor Latinoamericano.

NiColson, Harold (2012). La Diplomacia. México D.F.: Fondo de Cultura Económica.

NinO, Carlos (2014). Derecho, moral y política: Una revisión de la teoría general del derecho. Buenos Aires: Siglo XXI Editores.

PinTO-BAZurco, Ernesto (2011). "Derecho Internacional, Política Exterior y Diplomacia", en Revista Peruana de Derecho Internacional 142. Lima: Sociedad Peruana de Derecho Internacional.

QUINTANA, Fernando (2006). Interpretación y argumentación jurídica. Santiago: Editorial Jurídica de Chile.

QuiTRAL, Máximo (2010): “Chile y Bolivia: entre el abrazo de Charaña y sus relaciones económicas, 1975-1990.” en Universum 25 (2): 139-160.

Ramos, Carlos (2014). Cultura jurídica, proceso y hombres del foro. Cuatro ensayos de historia del derecho. Lima: Fundación Manuel J. Bustamante de la Fuente.

RENOUVIn, Pierre (1960). Historia de las Relaciones Internacionales. Madrid: Ed. Aguilar.

Renouvin, Pierre y Duroselle, Jean-Baptiste (2000). Historia de las Relaciones Internacionales. México D.F.: Fondo de Cultura Económica.

Rodríguez Elizondo, José (2014). Historia de dos demandas: Perú y Bolivia contra Chile. Santiago: Ed. El Mercurio Aguilar.

Rojas, René (1984). "El abogado y la diplomacia”, en Revista Chilena de Derecho 12(3). Santiago: Pontificia Universidad Católica de Chile.

SHAw, Malcolm (2012). International Law. Cambridge: Cambridge University Press.

SifueNTES, Marco y RiEPL, Martín (2014). El último cartucho. Cómo ganamos $50.000 \mathrm{~km}^{2}$ de mar en la Corte de La Haya. Lima: Editorial Planeta.

SILES, Jorge (2012). Sí, el Mar. La Paz: Plural Editores.

Sobrevilla, David (1973): “La influencia de Kelsen en el Perú. Una revisión crítica”. En Derecho PUCP 31. Lima: Pontificia Universidad Católica del Perú. 
Sobrevilla, David (2013). La filosofía del derecho en el Perú. Lima: Fondo Editorial Universidad de Lima.

Sorensen, Max, editor (2008). Manual de Derecho Internacional Público. México D.F.: Editorial Fondo de Cultura Económica.

SQUELLA, Agustín (1992). La cultura jurídica chilena. Santiago: Corporación de Promoción Universitaria.

SQuELLA, Agustín (2001): Filosofía del Derecho. Santiago: Editorial Jurídica de Chile.

SuPIOT, Alain (2012). Homo juridicus. Ensayo sobre la función antropológica del derecho. Buenos Aires: Siglo XXI editores.

TAPIA, Jorge y MARDONES, Luciano (2011). La mediterraneidad de Bolivia. Y el factor peruano. Santiago: Editorial Jurídica de Chile.

TARello, Giovanni (1995). Cultura Jurídica y Política del Derecho. México D.F.: Fondo de Cultura Económica.

TÉLlEZ, Eduardo (1989). Historia general de la frontera de Chile con Perú y Bolivia 1825 1929. Santiago: Editorial Universitaria.

TOMASSINI, Luciano (1989). Teoría y práctica de la política internacional: lecciones. Santiago: Ediciones Universidad Católica de Chile.

UlloA, Alberto (1926). Derecho Internacional Público. Lima: Sanmartí y Cía. Impresiones.

VAN KLAVEREN, Albert (2012) "La política del derecho internacional. El análisis de los regímenes internacionales", en LlANOS MARDONES, Hugo y PICAND, Eduardo (editores). Estudios de Derecho Internacional. Libro homenaje al profesor Hugo Llanos Mansilla. Santiago: Thomson Reuters.

ZapatA, Antonio (2012). "De Ancón a La Haya. Relaciones Diplomáticas entre Chile y Perú", en VArios Autores. Generación de Diálogo Chile - Perú/Perú Chile. Documento 2. Aspectos históricos. Lima: IDEI Pontificia Universidad Católica del Perú - Konrad Adenauer Siftung / Santiago: IEI Universidad de Chile: 11-28.

ZapatA, Antonio (2014): "La cuestión boliviana", en Argumentos 8(1). Lima, Instituto de Estudios Peruanos: 19-23. 